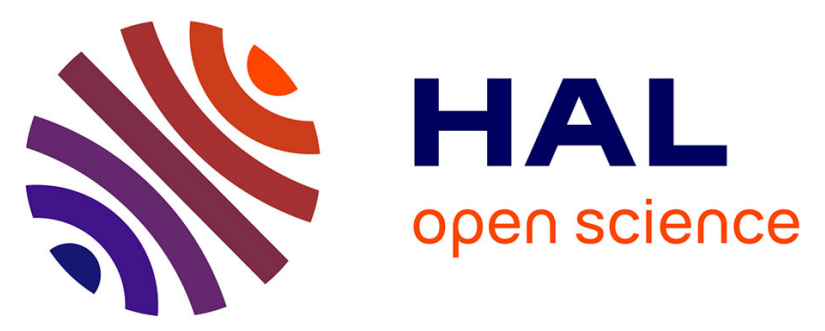

\title{
Micro- and macrovascular function in children with sickle cell anaemia and sickle cell haemoglobin $\mathrm{C}$ disease
}

Berenike Möckesch, Keyne Charlot, Stéphane Jumet, Marc Romana, Lydia

Divialle-Doumdo, Marie Hardy-Dessources, Marie Petras, Benoît Tressieres, Vanessa Tarer, Olivier Hue, et al.

\section{To cite this version:}

Berenike Möckesch, Keyne Charlot, Stéphane Jumet, Marc Romana, Lydia Divialle-Doumdo, et al.. Micro- and macrovascular function in children with sickle cell anaemia and sickle cell haemoglobin C disease. Blood Cells, Molecules and Diseases, 2017, 64, pp.23 - 29. 10.1016/j.bcmd.2017.02.001 . hal-01496857

\section{HAL Id: hal-01496857 https://hal.science/hal-01496857}

Submitted on 27 Mar 2017

HAL is a multi-disciplinary open access archive for the deposit and dissemination of scientific research documents, whether they are published or not. The documents may come from teaching and research institutions in France or abroad, or from public or private research centers.
L'archive ouverte pluridisciplinaire $\mathbf{H A L}$, est destinée au dépôt et à la diffusion de documents scientifiques de niveau recherche, publiés ou non, émanant des établissements d'enseignement et de recherche français ou étrangers, des laboratoires publics ou privés. 


\section{Micro- and macrovascular function in children with sickle cell anaemia and sickle cell haemoglobin C}

disease

Berenike Möckesch ${ }^{1,2,3}$, Keyne Charlot ${ }^{1,2,3}$, Stéphane Jumet ${ }^{1}$, Marc Romana ${ }^{2,3}$, Lydia Divialle-Doumdo ${ }^{4}$, MarieDominique Hardy-Dessources ${ }^{2,3}$, Marie Petras ${ }^{4}$, Benoît Tressieres ${ }^{5}$, Vanessa Tarer ${ }^{4}$, Olivier Hue ${ }^{1}$, Maryse Etienne-Julan ${ }^{4}$, Philippe Connes $2,3,6,7, *$ and Sophie Antoine-Jonville ${ }^{1, *}$

${ }^{1}$ Laboratory ACTES (EA 3596), French West Indies University, Pointe-à-Pitre, Guadeloupe, France; ${ }^{2} U M R$ Inserm U1134, French West Indies University, Pointe-à-Pitre, Guadeloupe, France; ${ }^{3}$ Laboratoire d'Excellence du Globule Rouge (LABEX GR-Ex), PRES Sorbonne, Paris, France; ${ }^{4}$ Sickle cell Center, Academic Hospital of Pointe-à-Pitre, Pointe-à-Pitre, Guadeloupe, France; ${ }^{5}$ Centre Investigation Clinique Antilles Guyane, 1424 Inserm, Academic Hospital of Pointe-à-Pitre, Pointe-à-Pitre, Guadeloupe, France; ${ }^{6}$ Institut Universitaire de France (IUF), Paris, France; 'Laboratory LIBM EA7424, Team "Vascular Biology and Red Blood Cell", University of Lyon 1, France

*equivalent position

Corresponding author: Sophie Antoine-Jonville, Laboratory ACTES (EA 3596), French West Indies University, Pointe-à-Pitre, Guadeloupe, France, [s_antoine@ymail.com], (+590) (0) 590483175 


\begin{abstract}
It is unclear whether vascular function, in micro- and macrocirculation, is affected similarly in children with sickle cell anaemia (SS) and children with sickle haemoglobin C (SC) disease. Therefore, we compared micro and macrovascular functions in healthy (AA) children, children with SS and SC disease. Moreover, given that physical activity is known to enhance vascular function in the general population, we investigated associations between vascular function and physical activity level in each group. Participants (24 SS, 22 SC and 16 AA), were compared in terms of 1) thermal hyperaemic response (finger pad warming to $42{ }^{\circ} \mathrm{C}$ ) measured by Laser Doppler techniques, 2) arterial stiffness determined by pulse wave velocity, 3) daily energy expenditure related to moderate and intense physical activities estimated by questionnaire and 4) fitness level, evaluated by the sixminute walk test. Response to heating differed between SS, SC and controls. Peripheral microvascular reactivity was lower and pulse wave velocity higher in SS compared to AA. SC had blunted microvascular reactivity in response to heating compared to AA but pulse wave velocity was not different within the two groups. Physical activity and fitness levels were markedly lower in sickle cell patients compared to healthy controls but no association was observed with vascular function. Microvasodilatory reserve is decreased in both SS and SC patients but only SS patients were also characterized by impaired macrovascular function.
\end{abstract}

Keywords: Vascular function, Sickle cell anaemia, sickle cell haemoglobin C disease, physical activity 


\section{Introduction}

Sickle cell disease (SCD) is a hereditary haemoglobinopathy characterised by red blood cell abnormalities (i.e., decreased deformability and increased fragility) leading to chronic anaemia and vascular occlusions [1]. The term SCD encompasses a group of symptomatic disorders defined by the presence of predominantly haemoglobin $\mathrm{S}$, or haemoglobin $\mathrm{S}$ along with other variants. The two most common forms are homozygous sickle cell disease (SS) and sickle haemoglobin C (SC) disease. SS was previously mainly considered as a haemorheological disease [2] but growing evidence suggest also the involvement of vascular dysfunction in the pathophysiology of this disease [3-5]. However, most of previous studies on vascular function in sickle cell patients concentrated on adults $[3,6-8]$. Whether vascular function is impaired from childhood on and which vascular compartments (i.e. micro- and/or macrocirculation) are primary affected, is still not clear, particularly in SC disease.

Micro- and macrocirculatory functions are designed to operate in a closely integrated manner. Coordination and regulated interplay throughout the vascular system are indispensable to maintain instantaneous adjustments [9]. However, haemodynamic parameters differ in micro- and macrocirculation [10]. Furthermore micro- and macrovascular systems distinguish in vascular structure, function and control mechanisms [10]. Thus, vascular function impairments may have different effects according to the circulatory level/vascular compartment affected. Arterial stiffness, known as an indicator for macrovascular function, has been analysed in sickle cell adults $[11,12]$ but whether arterial hardening also occurs in children and whether it is associated with microvascular dysfunction have never been assessed, especially in SC disease.

Physical activity is known to improve vascular function in healthy population and in different cardio-metabolic diseases $[13,14]$. The mechanisms involved are not yet well understood but regular aerobic exercise is supposed to stimulate nitric oxide (NO) production, to decrease oxidative stress and thereby enhances NO-bioavailability and arterial reactivity [13]. Although acute intense exercise may increase the risk of vaso-occlusive crises in sickle cell patients [15], a moderate submaximal exercise is generally well tolerated and do not extend risks of acute complications in these patients [16,17]. Studies performed with transgenic sickle mice further demonstrated an improvement of anti-oxidant defence and endothelial function as well as blood rheology by regular physical activity $[18,19]$. Whether regular physical activity in sickle cell patients can enhance vascular function remains unknown.

The primary aim of the present study was to determine and to compare micro- and macrovascular functions between children/adolescents with SS, SC disease and healthy children/adolescents. The second objective was to 
clarify whether the degree of vascular dysfunction in children/adolescents with sickle cell disease could be related to the level of regular physical activity/physical fitness.

\section{Materials and methods}

Study population

Sixty-two children/adolescents from 10 to 16 years old took part in the study, which was conducted in accordance to the Declaration of Helsinki and was approved by the Regional Ethics Committee (CPP Sud-Ouest Outre-Mer III, Bordeaux, France, registration number: 2009-A00211-56/2013, SAPOTILLE/HYPOSNAD project). This study included 24 SS patients (10 girls, 14 boys), 22 SC patients (13 girls, 9 boys) and 16 healthy control children with normal haemoglobin (AA; 8 girls, 8 boys), matched for ethnic origin (African Guadeloupians).

Children/adolescents with SCD were recruited from the Sickle Cell Unit of the Academic Hospital of Pointe-àPitre (Guadeloupe) where they are regularly followed since birth. They were at steady state at the time of the study (i.e., no blood transfusion within the last three months, absence of acute episodes of infection, vasoocclusive crisis or acute chest syndrome at least one month before inclusion in the study). Four patients were under hydroxyurea treatment for more than six months (dose $\sim 20 \mathrm{mg} / \mathrm{kg}$ per day).

\section{Design of the study}

When all annual examinations were done and blood samples were taken, each child answered an appropriate questionnaire concerning their daily physical activity. Then, all children were equipped and remained on a comfortable bed in lying position in a quiet room (room temperature fixed at $\sim 24^{\circ} \mathrm{C}$, skin temperature $\sim 33^{\circ} \mathrm{C}$ ). After a 10-min baseline recording, local thermal hyperaemia was conducted for $40 \mathrm{~min}$. Afterwards pulse-wave velocity (PWV) was measured. Children with SCD also performed a 6-minute walk test (6MWT) under medical surveillance.

\section{Haematological and blood viscosity measurements}

Venous blood was sampled in sitting position from the antecubital vein in children with haemoglobin SS and SC. Haematological and haemorheological parameters were measured within 1-2 hours after sampling and after full reoxygenation of blood for 10-15 $\mathrm{min}$ as recommended [20]. Haemolytic indicators like serum lactate dehydrogenase concentration, bilirubin levels, reticulocyte counts (expressed as a percentage) and aspartate aminotransferase content were determined by standard biochemical methods. The haemolytic component value was derived from haemolytic markers (bilirubin, lactate dehydrogenase, aspartate aminotransferase and reticulocytes) by principal component analysis [21]. Foetal haemoglobin level was quantified using cation- 
exchange high performance liquid chromatography (VARIANTTM, Bio-Rad Laboratories, Hercules, CA, USA) and haematological data were obtained using an automated cell counter (Beckman Coulter MAXM AL, FL, USA). Blood viscosity was measured at native haematocrit and at room temperature $\left(25^{\circ} \mathrm{C}\right)$ using a cone-plate viscometer (Brookfield DVII+ with CPE40 spindle, Brookfield Engineering Labs. Natick, MA, USA) at $225 \mathrm{~s}^{-1}$. Measurements were performed according to the recent international guidelines for haemorheological laboratory techniques [20].

\section{Assessment of microvascular function by heat-mediated vasodilation}

In all children, peripheral microcirculatory cutaneous blood flow and microvascular response to local heating were evaluated using a Laser Doppler flowmeter (Periflux System 5000, Perimed, Järfälla, Sweden) and its associated software Perisoft (Perimed), which enables continuous skin blood flow recording (mV). A combined laser Doppler and thermostatic metallic probe (PR457) was attached to the distal pad of the middle finger of the left hand. After a 10-min baseline recording, skin temperature was raised to $42^{\circ} \mathrm{C}$ (within 5 s) and the microvascular response to local heating was measured for $40 \mathrm{~min}$. Local cutaneous heating results in a biphasic increase in blood flow: a rapid increase (initial peak) related to axon reflex followed by a nadir and a prolonged plateau mainly NO-dependent [22,23]. Taking into account any individual fluctuations of skin blood flow (due to blood pressure changes), laser Doppler blood flow (perfusion unit, recorded in $\mathrm{mV}$ ) was divided by the individual mean arterial pressure (MAP). In this way, baseline blood flow, initial peak and the plateau were expressed as cutaneous vascular conductance (CVC, $\mathrm{mV} / \mathrm{mmHg})$ [24]. Reactive hyperaemia was calculated as percentage change in flow during thermal stress (peak and plateau) compared with baseline as previously recommended [22,23]. Increase of skin blood flow up to peak and up to plateau served as indicators for microvascular function $[22,23]$.

Non-Invasive assessment of arterial stiffness by pulse wave velocity

Arterial stiffness, assessed by PWV, can be considered as an indicator of macrovascular function [25]. In this study, we measured PWV (m/s) from the carotid to radial (CR-PWV) arteries with a non-invasive automated device (SphygmoCor System, Actor, Sydney, Australia) using an arterial tonometer for recording pressure waveforms and a 3-lead electrocardiogram. PWV is defined as the distance between the measuring sites divided by the transit time (in seconds) of the related pulse waves. Transit time is defined as the difference between the delay of the distal pulse wave to the R wave of the ECG and the delay of the proximal pulse wave to R wave of the ECG. The pulse wave delay can be determined by calculating the time elapsed from the peak of the R wave and the foot of the pressure pulse wave. 
The device used here is highly reproducible (inter- and intra-operator) in both healthy and diseased populations [26]. Measurements were obtained by the same experienced operator during the whole study and repeated two times for each site of measurement, but only the mean value was retained. Additional we recorded heart rate (bpm), resting diastolic blood pressure ( $\mathrm{DBP}, \mathrm{mmHg}$ ), resting systolic blood pressure ( $\mathrm{SBP}, \mathrm{mmHg}$ ), pulse pressure $($ Pulse pressure $=\mathrm{SBP}-\mathrm{DBP}($ in $\mathrm{mmHg})$ and mean arterial pressure $(\mathrm{MAP}=(2 * \mathrm{DBP}+\mathrm{SBP}) / 3)$.

\section{Physical activity questionnaire for children/adolescents}

Each child answered the International Physical Activity Questionnaire adapted for adolescents [27]. The questionnaire involved physical activities related to the mode of transportation to and from school (walking, bicycling or motor vehicle), physical activities inside and outside school settings, as well as leisure-time activities to estimate the level of physical activity energy expenditure (PAEE). Therefore each activity has been associated with a number of metabolic equivalent, which was then multiplied by the corresponding activity duration (min). PAEE represents the sum of all moderate to intense physical activities. Afterwards, PAEE has been adjusted to weight and resting metabolic rate according to Buchowski et al [28]. Finally, PAEE was expressed as $\mathrm{kcal} / \mathrm{day}$.

\section{Six-minute walk test (6MWT)}

Physical fitness was measured in all children with SCD by the 6MWT, which was performed according to the guidelines set by the American Thoracic Society [29]. The 6MWT is not correlated with maximal exercise capacity in children with SCD and young adults but reflects the functional exercise level for daily physical activities since most activities of daily living are performed at submaximal levels of exertion [30]. During 6 minutes, the participant has to walk as fast as possible, without running. Then the distance walked was noted and the percentage of predicted distance was calculated by Geigers' standardized formula [31] according to age, sex and height, as previously done [32]. The 6MWT was considered as normal if the performance was more than $80 \%$ of the age-standardised predicted value and abnormal otherwise [33].

\section{Statistics}

The results are presented as mean \pm standard deviation or median $\left(25^{\text {th }}\right.$ and $75^{\text {th }}$ percentiles $)$. After testing the normality and homogeneity of variance, we compared anthropometric, physiological, microvascular, macrovascular and physical activity parameters between the three groups using a one-way analysis of variance (ANOVA) followed by a Newman-Keuls post-hoc test. Kruskall Wallis Anova was applied for non-parametric parameters (body mass index, MAP, PAEE, percentage blood flow increase up to peak and up to plateau). 
Haemorheological and biological parameters were measured in SS and SC patients only and compared between the two patient groups using unpaired Student $t$ test or Mann-Whitney comparison test. Parametric or nonparametric correlation tests (Pearson or Spearman, respectively) were performed in each group (AA, SC and SS) in order to test the associations between micro- and macrovascular function and to identify whether physical activity and vascular function parameters were associated. The significance level was defined as $P<0.05$. Analyses were conducted using SPSS (v. 20, IBM SPSS Statistics, Chicago, IL) and Statistica (Statistica, v5.5, Statsoft, Tulsa, OK, USA).

\section{Results}

\section{Population characteristics}

A total of 62 children with similar anthropometric characteristics were enrolled in the study (Table 1). SBP, DBP and MAP did not differ significantly between patients and controls whereas pulse pressure was significantly higher in SS patients compared to SC patients $(P=0.013)$ but not different to controls (Table 1). As expected, haemoglobin, haematocrit levels and blood viscosity were significantly lower in SS than in SC patients $(P<$ 0.001, Table 1). Haemolytic parameters (lactate dehydrogenase, bilirubin, reticulocytes, aspartate aminotransferase, haemolytic index) and foetal haemoglobin were significantly higher in SS compared to SC patients $(P<0.001$, Table 1$)$. In both groups, no correlation was observed between vascular function, physical activity parameters and haemolytic parameters (data not shown).

\section{Microvascular function}

All data are reported in Table 2 and Fig 1 . Baseline blood flow was significantly higher in SS than in SC $(P<$ $0.05)$ and healthy $(P<0.01)$ children. No association was found between baseline blood flow and haematocrit level in SS and SC group. In response to local heating, peak and plateau blood flow were not different between the three groups. However, when expressed as a percentage (Fig 1), the increase of skin blood flow up to peak and plateau were higher in controls than in SS patients $(P=0.004$ and $P=0.001$, respectively). SC patients showed a blunted "peak" response compared to controls $(P=0.03)$ whereas flow increase up to plateau (expressed as a percentage) was not statistically different from controls $(P=0.08)$. No association was found in SS or SC patients between haematocrit or haemoglobin and vascular reactivity.

\section{Macrovascular function}


SS patients had statistically higher CR-PWV compared to controls $(P=0.03$, Fig 2$)$ and no correlation was found between CR-PWV and blood viscosity or haematocrit level (data not shown). CR-PWV of SC patients was not different from AA or SS values. Macrovascular function (CR-PWV) was related to microvascular function (blood flow increase up to plateau) in children with SS $(r=-0.57, P=0.04)$ but not in children with SC $(P=0.72)$ and controls $(P=0.81)$.

\section{Physical activity level and physical fitness}

Daily energy expenditure related to moderate and intense physical activities (PAEE) was significantly lower in both sickle cell groups compared to controls $(P=0.02$, Fig 3 A). $78 \%$ of patients (SS: $79 \%$, SC: $77 \%)$ performed an abnormal 6MWT compared to the age-standardised predicted distance (Fig 3B). However, there was no statistically significant difference in total walk distance between the two sickle groups. Statistical analysis revealed that neither micro- nor macrovascular function was correlated to PAEE or walked distance in each group (data not shown).

\section{Discussion}

The major findings are that SS patients present abnormal microvascular reactivity compared to AA. Both microand macrovascular function appeared to be affected in children with homozygous sickle cell disease. Only neurological related microvascular response to heating (percentage of flow increase from baseline to peak) was decreased in SC compared to AA. Furthermore, physical activity and fitness levels were markedly affected in children with SCD but no association was observed with vascular parameters.

\section{Vascular function}

According to previous findings, baseline blood flow was increased in SS. Severe anaemia and increased cardiac output participate to the rise in blood flow [6]. As a consequence, vascular wall shear stress is supposed to raise [6], promoting nitric oxide production to stimulate vasodilation in order to compensate for elevated shear rate, so as to finally normalize wall shear stress [6]. In this study, no correlation could be observed between haematocrit level and vascular reactivity or baseline blood flow. Our findings are in agreement with previous studies [36]. Anaemia leads to important cardiovascular adaptions in order to compensate for the decrease in haematocrit, but vascular impairments in SCD may result from multiple sources [37]. As previously demonstrated, vascular function appears to be impaired in SS [38]. Decreased NO bioavailability, as a consequence of intravascular haemolysis and oxygen free radical production [38,39], are suspected to impair vascular function in SS patients 
$[6,7,40]$. This study illustrated that NO-dependent vasodilation (Plateau phase) as well as neurological control mechanisms (axon reflex) of peripheral microcirculation were altered in young SS patients. Vascular control is relevant for compensation of flow resistance. In this context, it is suspected that any increase in blood viscosity in SS patients with vascular dysfunction would lead to a rise in vascular resistance, which may probably slow blood flow and therefore could promote sickling and, thus, painful vaso-occlusive crises [41].

Chronic vasculopathy has been reported to affect also large blood vessels in SS and is supposed to rise risks for several complications such as stroke [5] and pulmonary hypertension [42]. Unlike previous work in sickle cell adults [11], our findings suggest an increase of peripheral arterial stiffness in SS compared to AA group. Although peripheral arterial stiffness cannot be considered as a principal indicator of arterial hardening compared to central arterial stiffness, our results indicate that SC and SS patients do not respond in a similar manner. Blood viscosity was significantly higher in SC than in SS. The impact of abnormal blood rheology on PWV has been poorly investigated and is debated [43-47]. Most of the patients with cardiovascular diseases, such as obesity, sleep apnea or atherosclerosis are characterized by both increased PWV and impaired blood rheology [48-50] but whether increased PWV is due to increased blood viscosity is unknown. In this study, correlations analyses do not suggest any association between haematocrit or blood viscosity and PWV but further works are needed to address this question in sickle cell disease, as well as in cardiovascular diseases in general. Despite the difference in PWV found between SS and AA, blood pressure parameters were similar in all the three groups. Decreased functionality in peripheral microcirculation and increased stiffness in larger peripheral arteries were significantly correlated in children with SS, suggesting that the same mechanisms could be involved and responsible for these dysfunctions.

SS and SC differ in several haemorheological, haemodynamic and clinical outcomes [51,52]. SC was previously considered as a less severe sickle cell syndrome than SS but nowadays several authors [34,53] suggest that these two genotypes should be rather seen as two distinct diseases. SS patients are usually exposed more frequently to vaso-occlusive crises and haemolysis, favouring possibly the development of chronic micro- and macrovascular dysfunctions, as suggested in the present study. In contrast, SC patients are usual more likely to develop retinopathy, osteonecrosis and thromboembolism which has been associated to the higher blood viscosity compared to SS [34,35]. Baseline blood flow and micro- and macrovascular function in children with SC tend to be normal, regarding statistical analysis, except for the initial response to heating which suggest, like in children with SS, blunted axonal reflex vasodilatory response [23]. Further studies are needed to address the exact mechanisms. Although SC patients are marked by blood hyperviscosity, it appears that NO-dependent vascular 
function and vessels elasticity are preserved which may enable normalization of vascular resistance and may reduce the risk of painful vaso-occlusive crises [54]. Children with sickle cell haemoglobin C disease had also a low pulse pressure, which is probably the consequence of well-functioned central and peripheral arterial elasticity [55]. This may lower the risks for cardiovascular co-morbidities [56]. Nevertheless the representation of blood flow increase up to plateau revealed large intragroup difference. Some SC patients responded like controls whereas the majority reached values comparable to SS patients. Higher sample size would be necessary to clarify the reasons for this heterogeneity. Regarding the clinical charts, none of the participants of this study had signs of glomerulopathy or retinopathy. A next step would be to follow these children in a prospective way in order to test whether children with marked vascular dysfunction are more likely to develop vasculopathy than those with retained vascular reactivity.

\section{Physical activity level and fitness}

The time spent for moderate and intense physical activity was decreased in both SS and SC compared to healthy controls. In addition, the two groups exhibited a low performance at the 6MWT.

It has been reported that SS patients are characterised by greater resting energy expenditure than their healthy counterparts due to higher protein turnover and higher cardiac output $[57,58]$. In order to maintain total energy expenditure to normal level, physical activity energy expenditure is decreased [60] resulting in low physical fitness level. Mechanisms responsible for this exercise limitation are partly known in SS patients. We may mention chronic anaemia [59], haemorheological alterations [60], pulmonary dysfunction [61], increased arterial hypoxemia [62], chronic haemolysis and vascular function impairments [61]. Exercise responses in SC patients are not yet well studied. Although vascular function seems to be better preserved in children with SC, both sickle cell groups had a decreased exercise capacity compared to healthy children. In SC, mild anaemia and blood hyperviscosity could be responsible for decreased physical fitness, due to their known adverse effects on tissue oxygenation [64].

\section{Vascular function, physical activity level and fitness}

This study is the first to explore the associations between vascular function and physical activity level in children with sickle cell disease. Regular physical activity is known to improve NO production and bioavailability and to decrease oxidative stress [13,14]. Several studies in various chronic diseases demonstrated improved vascular function by regular physical activity $[13,63]$. However we could not observe any correlation between regular physical activity/fitness and vascular parameters, neither in SS, nor in SC patients. In our paediatric cohort, 
physical activity level was probably to low [14] to induce large biological and physiological adaptations, which could enhance physical fitness and vascular function. The use of accelerometer in future studies could be useful to quantify physical activity level. Recent studies with transgenic sickle mice demonstrated that regular physical activity was able to decrease oxidative stress and improve endothelial function [19,64]. A large prospective and longitudinal study in children with SCD would be needed to clarify the effects of a moderate training rehabilitation program on the clinical outcome and the potential physiological benefits.

\section{Conclusion}

In conclusion, peripheral micro- and macrovascular functions were reduced and associated to each other in SS children/adolescents. Micro- and macrovascular functions in SC appear to be better preserved than in SS. No association was found between physical activity- and vascular function parameters. Further research is necessary to differentiate mechanisms involved in SS and SC pathophysiology and to clarify the potential benefits of physical activity on vascular function in patients with SCD.

\section{Acknowledgements}

This work was supported by the Academic hospital of Pointe-à-Pitre grant B91122-40 (2009-A00211-56). The authors would like to thank the patients who participated in the study.

Conflict of interest: The authors declare to not have any conflict of interest.

\section{Author contributions}

Ms Möckesch and Dr Charlot designed the data collection instruments, coordinated and supervised data collection, carried out the study, conducted the statistical analyses, drafted the initial manuscript and approved the final manuscript. Mr Jumet designed the data collection instruments, coordinated and supervised data collection, carried out the study and approved the final manuscript. Dr Romana designed the study, drafted the initial manuscript and approved the final manuscript. Drs Divialle-Doumdo and Petras, Mr Tressières and Ms Tarer carried out the study and approved the final manuscript. Dr Hardy-Dessources designed the study and critically reviewed and approved the final manuscript. Dr Hue approved the final manuscript. Dr Etienne-Julan designed the study and approved the final manuscript. Drs Connes and Antoine-Jonville designed the study and the data collection instruments, coordinated and supervised data collection, carried out the study, conducted the statistical analyses, drafted the initial manuscript and approved the final manuscript. 


\section{References}

[1] D. Rees, T.N. Williams, M.T. Gladwin, Sickle-cell disease, Lancet. 376 (2010) 2018-2031.

[2] S. Chien, S. Usami, J.F. Bertles, Abnormal rheology of oxygenated blood in sickle cell anemia., J. Clin. Invest. 49 (1970) 623-34.

[3] M.T. Gladwin, A.N. Schechter, F.P. Ognibene, W. A. Coles, C.D. Reiter, W.H. Schenke, G. Csako, M.A. Waclawiw, J. A. Panza, R.O. Cannon, Divergent nitric oxide bioavailability in men and women with sickle cell disease, Circulation. 107 (2003) 271-278.

[4] D.K. Kaul, X.-D. Liu, M.E. Fabry, R. Nagel, Impaired nitric oxide - mediated vas o dilation in transgenic sickle mouse, Am J Physiol Hear. Circ Phsiol. 278 (2000) 1799-1806.

[5] P. Connes, S. Verlhac, F. Bernaudin, Advances in understanding the pathogenesis of cerebrovascular vasculopathy in sickle cell anaemia, Br. J. Haematol. 161 (2013) 484-498.

[6] L. Belhassen, G. Pelle, S. Sediame, D. Bachir, C. Carville, C. Bucherer, C. Lacombe, F. Galacteros, S. Adnot, Endothelial dysfunction in patients with sickle cell disease is related to selective impairment of shear stress-mediated vasodilation, Blood. 97 (2001) 1584-1589.

[7] P. Tharaux, R. Girot, A. Kanfer, J. Dussaule, J. Gaitz, et al. Tribout L, Cutaneous microvascular blood flow and reactivity in patients with homozygous sickle cell anaemia, Eur. J. Haematol. 68 (2002) 32731.

[8] J. Mohan, G. Lip, A. Blann, D. Bareford, J. Marshall, Endothelium-dependent and endotheliumindependent vasodilatation of the cutaneous circulation in sickle cell disease, Eur. J. Clin. Invest. 41 (2011) 546-551.

[9] R. Klabunde, Cardiovascular physiology concepts, 2nd ed., Lippincott Williams\&Wilkins, 2005.

[10] M.E. Safar, H. A. Struijker-Boudier, Cross-talk between macro- and microcirculation, Acta Physiol. 198 (2010) 417-430.

[11] D. Lemogoum, L. Van Bortel, B. Najem, A. Dzudie, C. Teutcha, E. Madu, M. Leeman, J.P. Degaute, P. Van De Borne, Arterial stiffness and wave reflections in patients with sickle cell disease, Hypertension. 44 (2004) 924-929.

[12] B. Ranque, F. Jouven, Prognostic value of pulse wave velocity in sickle cell disease: the cadre study, Cardiovasc. J. Afr. 24 (2013) 28.

[13] G. Kojda, R. Hambrecht, Molecular mechanisms of vascular adaptations to exercise. Physical activity as an effective antioxidant therapy?, Cardiovasc. Res. 67 (2005) 187-197.

[14] D. Green, A. Maiorana, G. O’Driscoll, R. Taylor, Effect of exercise training on endothelium- derived nitric oxide function in humans, J. Physiol. 561 (2004) 1-25.

[15] X. Waltz, P. Connes, Pathophysiology and physical activity in patients with sickle cell anemia, Mov. Sport. Sci. - Sci. Mot. 83 (2014) 41-47.

[16] E. Balayssac-Siransy, P. Connes, N. Tuo, C. Danho, M. Diaw, I. Sanogo, M.-D. Hardy-Dessources, A. Samb, S.K. Ballas, P. Bogui, Mild haemorheological changes induced by a moderate endurance exercise in patients with sickle cell anaemia, Br. J. Haematol. 154 (2011) 398-407. doi:10.1111/j.13652141.2011.08728.x.

[17] P. Barbeau, K.F. Woods, L.T. Ramsey, M.S. Litaker, D.M. Pollock, J.S. Pollock, L.A. Callahan, A. Kutlar, G.A. Mensah, B. Gutin, Exercise in sickle cell anemia: effect on inflammatory and vasoactive mediators, Endothelium. 8 (2001) 147-155.

[18] C. Faes, E. Charrin, P. Connes, V. Pialoux, C. Martin, Chronic physical activity limits blood rheology alterations in transgenic SAD mice, Am. J. Hematol. 90 (2015) E32-E33.

[19] E. Charrin, E. Aufradet, A. Douillard, A. Romdhani, G. Souza, A. DeBessaad, C. Faes, E.N. Chirico, V. Pialoux, C. Martin, Oxidative stress is decreased in physically active sickle cell SAD mice, Br. J. Haematol. 168 (2014) 747-56.

[20] O.K. Baskurt, M. Boynard, G.C. Cokelet, P. Connes, B.M. Cooke, S. Forconi, F. Liao, M.R. Hardeman, F. Jung, H.J. Meiselman, G. Nash, N. Nemeth, B. Neu, B. Sandhagen, S. Shin, G. Thurston, J.L. 
Wautier, New guidelines for hemorheological laboratory techniques, Clin. Hemorheol. Microcirc. 42 (2009) 75-97.

[21] M. Nouraie, J.. Lee, Y. Zhang, M.T. Gladwin et al, the relationship between the severity of hemolysis, clinical manifestations and risk of death in 415 patients with sickle cell anemia in the US and Europe, Haematologica. 98 (2013) 464-472.

[22] C. Minson, L. Berry, M. Joyner, Nitric oxide and neurally mediated regulation of skin blood flow during local heating, J. Appl. Physiol. 91 (2001) 1619-26.

[23] M. Roustit, J.-L. Cracowski, Non-invasive assessment of skin microvascular function in humans: an insight into methods., Microcirculation. 19 (2012) 47-64.

[24] A. Boignard, M. Salvat-Melis, P. Carpentier, C. Minson, L. Grange, C. et al. Duc, Local hyperemia to heating is impaired in secondary Raynaud's phenomenon, Arthritis Res Ther. 7 (2005) 1103-12.

[25] H. Tomiyama, A. Yamashina, Non-Invasive Vascular Function Tests:, Circ. J. 74 (2010) 24-33.

[26] I.B. Wilkinson, I.R. Hall, H. MacCallum, I.S. Mackenzie, C.M. McEniery, B.J. Van der Arend, Y.E. Shu, L.S. MacKay, D.J. Webb, J.R. Cockcroft, Pulse-wave analysis: Clinical evaluation of a noninvasive, widely applicable method for assessing endothelial function, Arterioscler. Thromb. Vasc. Biol. 22 (2002) 147-152.

[27] D. Arvidsson, F. Slinde, L. Hulthèn, Physical activity questionnaire for adolescents validated against doubly labelled water., Eur. J. Clin. Nutr. 59 (2005) 376-383.

[28] M.S. Buchowski, K.Y. Chen, D. Byrne, W.C. Wang, Equation to estimate resting energy expenditure in adolescents with sickle cell anemia, Am. J. Clin. Nutr. 76 (2002) 1335-44.

[29] R.O. Crapo, R. Casaburi, A.L. Coates, P.L. Enright, N.R. MacIntyre, R.T. McKay, D. Johnson, J.S. Wanger, R.J. Zeballos, V. Bittner, C. Mottram, ATS statement: Guidelines for the six-minute walk test, Am. J. Respir. Crit. Care Med. 166 (2002) 111-117. doi:10.1164/rccm.166/1/111.

[30] R. Liem, M. Nevin, A. Prestridge, L. Young, A. Thompson, Functional capacity in children and young adults with sickle cell disease undergoing evaluation for cardiopulmonary disease., Am. J. Hematol. 84 (2009) 645-649.

[31] R. Geiger, A. Strasak, B. Treml, K. Gasser, A. Kleinsasser, V. Fischer, H. Geiger, A. Loeckinger, J.I. Stein, Six-minute walk test in children and adolescents., J. Pediatr. 150 (2007) 395-399, 399.e1-e2.

[32] X. Waltz, M. Romana, M.-D. Hardy-Dessources, P. Connes et al, Hematological and hemorheological Determinants of the Six-Minute Walk Test Performance in Children with Sickle Cell Anemia, PLoS One. 8 (2013).

[33] L. Dedeken, R. Chapusett, P. Lê, C. Heijmans, C. Devalck, S. Huybrechts, F. Ziereisen, L. Hanssens, L. Rozen, D. Noubouossie, M. Mujinga, A. Ferster, Reduction of the Six-Minute Walk Distance in Children with Sickle Cell Disease Is Correlated with Silent Infarct: Results from a Cross-Sectional Evaluation in a Single Center in Belgium, PLoS One. 9 (2014).

[34] F. Lionnet, N. Hammoudi, K. Stojanovic, V. Avellino, G. Grateau, R. Girot, J. Haymann, Hemoglobin sickle cell disease complications: a clinical study of 179 cases., Haematologica. 97 (2012) 1136-1141.

[35] N. Lemonne, Y. Lamarre, M. Romana, M.-D. Hardy-Dessources, F. Lionnet, X. Waltz, V. Tarer, D. Mougenel, B. Tressières, M.-L. Lalanne-Mistrih, M. Etienne-Julan, P. Connes, Impaired blood rheology plays a role in the chronic disorders associated with sickle cell-hemoglobin C disease, Haematologica. 99 (2014) e74-e75.

[36] E. Nur, Y. Kim, J. Truijen, E.J. van Beers, S.C. Davis, D.P. Brandjes, B.J. Biemond, J.J. van Lieshout, Cerebrovascular reserve capacity is impaired in patients with sickle cell disease, Blood. 114 (2009) 3473-3478.

[37] G.J. Kato, R.P. Hebbel, M.H. Steinberg, M.T. Gladwin, Vasculopathy in sickle cell disease: Biology, pathophysiology, genetics, translational medicine, and new research directions, Am. J. Hematol. 84 (2009) 618-625.

[38] G.J. Kato, M.T. Gladwin, M.H. Steinberg, Deconstructing sickle cell disease: Reappraisal of the role of hemolysis in the development of clinical subphenotypes, Blood Rev. 21 (2007) 37-47.

[39] A. Mack, G. Kato, Sickle cell disease and nitric oxide: A paradigm shift?, Int. J. Biochem. Cell Biol. 38 
(2005) 1237-43.

[40] M. Aslan, T.M. Ryan, B. Adler, T.M. Townes, D. Parks, J. Thompson, A. Tousson, M.T. Gladwin, R.P. Patel, M.M. Tarpey, I. Batinic-Haberle, C.R. White, B.A Freeman, Oxygen radical inhibition of nitric oxide-dependent vascular function in sickle cell disease., Proc. Natl. Acad. Sci. U. S. A. 98 (2001) $15215-15220$.

[41] C.D. Reiter, M.T. Gladwin, An emerging role for nitric oxide in sickle cell disease vascular homeostasis and therapy, Curr. Opin. Hematol. (2003) 99-107.

[42] K. Charlot, M. Romana, B. Möckesch, S. Jumet, X. Waltz, E. Al, Which side of the balance determines the frequency of vaso-occlusive crises in children with sickle cell anemia: Blood viscosity or microvascular dysfunction, Blood Cells, Mol. Dis. 56 (2016) 41-45.

[43] F. Gladwin, M.T., Sachdev, V., Jison, M.L., Shizukuda, Y., Plehn, J.F., Minter, K., Brown, B., Coles, W.A., Nichols, J.S., Ernst, I., Hunter, L.A., Blackwelder, W.C., Schechter, A.N., Rodgers, G.P., Castro, O., \& Ognibene, Pulmonary hypertension as a risk factor for death in patients with sickle cell disease, $\mathrm{N}$. Engl. J. Med. 350 (2004) 886-895.

[44] R. Kawamoto, Y. Tabara, K. K, A slightly low haemoglobin level is beneficially associated with arterial stiffness in Japanese community-Dwelling Women, Clin.And Exp Microcirc. 55 (2013) 193-203.

[45] K. Parkhurst, H.. Lin, A. DeVan, Contribution of blood viscosity in the assessment of flow-mediated dilation and arterial stiffness, Vasc. Med. 17 (2012) 231-234.

[46] Y. Ikenaga, S. Nishi, Y. Komagata, Experimental study on the pressure and pulse wave propagation in viscoelastic vessel tubes effects of liquid viscosity and tube stiffness, IEEE Trans Ultrason Ferroelectr. Freq Control. 60 (2013) 2381-8.

[47] J. Kim, J. Yoon, M. Cho, B. Lee, Blood characteristics effect on pulse wave velocity, Clin Hemorheol Microcirc. 55 (2013) 193-203.

[48] Y. Li, X.. Tian, T. Liu, Association between whole blood viscosity and arterial stiffness in patients with type 2 diabetes mellitus, Endocrine. 49 (2015) 148-154.

[49] D. Toraldo, F. Peverini, M. De Benedetto, F. De Nuccio, Obstructive sleep apnea syndrome: blood viscosity, blood coagulation abnormalities and early atherosclerosis, Lung. 191 (2013) 1-7.

[50] M. Guiraudou, E. Varlet-Marie, E. Raynaud de Mauverger, J. Brun, Obesity-related increase in whole blood viscosity includes different profiles according to fat localization, Clin. Hemorheol. Microcirc. 55 (2013) 63-73.

[51] A. Lee, P.I. Mowbray, G.D. Lowe, A. Rumley, F.G.. Fowkes, P.. Allan, Blood viscosity and elevated carotid Intima-Media thickness in men and women, Circulation. 97 (1998) 1467-73.

[52] J. Tripette, T. Alexy, M.-D. Hardy-Dessources, D. Mougenel, E. Beltan, T. Chalabi, R. Chout, M. Etienne-Julan, O. Hue, H.J. Meiselman, P. Connes, Red blood cell aggregation, aggregate strength and oxygen transport potential of blood are abnormal in both homozygous sickle cell anemia and sicklehemoglobin C disease, Haematologica. 94 (2009) 1060-1065. doi:10.3324/haematol.2008.005371.

[53] Y. Lamarre, M. Romana, X. Waltz, M.-L. Lalanne, B. Tressières, L. Divialle-Doumdo, M.-D. Hardy, J. Vent-Schmidt, M. Petras, C. Broquere, F. Maillard, V. Tarer, M. Etienne-Julan, P. Connes, Hemorheological risk factors of acute chest syndrome and painful vaso-occlusive crisis in children with sickle cell disease, Haematologica. 97 (2012) 1641-1647.

[54] A. Hannemann, E. Weiss, D. Rees, S. Dalibalta, J. Ellory, J. Gibson, The Properties of Red Blood Cells from Patients Heterozygous for HbS and HbC (HbSC Genotype)., Anemia. (2011).

[55] Y. Lamarre, M.-D. Hardy-Dessources, M. Romana, M.-L. Lalanne-Mistrih, X. Waltz, M. Petras, L. Doumdo, A. Blanchet-Deverly, J. Martino, B. Tressières, F. Maillard, V. Tarer, M. Etienne-Julan, P. Connes, Relationships between systemic vascular resistance, blood rheology and nitric oxide in children with sickle cell anemia or sickle cell-hemoglobin C disease, Clin. Hemorheol. Microcirc. 58 (2014) 307316.

[56] M. Safar, B. Balkau, C. Lange, S. Protogerou, AD. Czernichow, J. Blacher, B. Levy, H. Smulyan, Hypertension and Vascular Dynamics in Men and Women With Metabolic Syndrome, J. Am. Coll. Cardiol. 62 (2013) 12-19. 
Pulse Pressure is Associated with Hemolysis, Proteinuria and Chronic Kidney Disease in Sickle Cell Disease, PLoS One. 9 (2014).

[58] E.M. Barden, B.S. Zemel, D.A. Kawchak, M.I. Goran, K. Ohene-Frempong, V.A. Stallings, Total and resting energy expenditure in children with sickle cell disease, J Pediatr. 136 (2000) 73-79.

[59] M.J. Borel, M.S. Buchowski, E.A. Turner, B.B. Peeler, R.E. Goldstein, P.J. Flakoll, Alterations in basal nutrient metabolism increase resting energy expenditure in sickle cell disease, Am. J. Physiol. 274 (1998) E357-E364.

[60] M.S. Buchowski, K.M. Townsend, R. Williams, K.Y. Chen, Patterns and energy expenditure of freeliving physical activity in adolescents with sickle cell anemia, J. Pediatr. 140 (2002) 86-92.

[61] P. Connes, R. MacHado, O. Hue, H. Reid, Exercise limitation, exercise testing and exercise recommendations in sickle cell anemia, Clin. Hemorheol. Microcirc. 49 (2011) 151-163.

[62] L.A. Callahan, K.F. Woods, G.A. Mensah, L.T. Ramsey, P. Barbeau, B. Gutin, Cardiopulmonary responses to exercise in women with sickle cell anemia, Am. J. Respir. Crit. Care Med. 165 (2002) 1309-1316.

[63] X. Waltz, M. Romana, M.-L. Lalanne-Mistrih, R.F. Machado, Y. Lamarre, V. Tarer, M.-D. HardyDessources, B. Tressières, L. Divialle-Doumdo, M. Petras, F. Maillard, M. Etienne-Julan, P. Connes, Hematologic and hemorheological determinants of resting and exercise-induced hemoglobin oxygen desaturation in children with sickle cell disease, Haematologica. 98 (2013) 1039-1044.

[64] X. Waltz, M.-D. Hardy-Dessources, N. Lemonne, D. Mougenel, M.-L. Lalanne-Mistrih, Y. Lamarre, V. Tarer, B. Tressieres, M. Etienne-Julan, O. Hue, P. Connes, Is there a relationship between the hematocrit-to-viscosity ratio and microvascular oxygenation in brain and muscle?, Clin. Hemorheol. Microcirc. 59 (2015) 37-43.

[65] K. Watts, P. Beye, A. Siafarikas, E. a. Davis, T.W. Jones, G. O'Driscoll, D.J. Green, Exercise training normalizes vascular dysfunction and improves central adiposity in obese adolescents, J. Am. Coll. Cardiol. 43 (2004) 1823-1827.

[66] C. Martin, V. Pialoux, C. Faes, E. Charrin, P. Connes, Does physical activity increase or decrease the risk of sickle cell disease complications?, Br. J. Sports Med. (2015).

[67] C. Renoux, M. Romana, Pialoux V et al, Effect of age on blood rheology in sickle cell anaemia and sickle cell haemoglobin C disease: a cross-sectional study, PLoS One. 11 (2016). 
Table 1. Population characteristics of children with SCD and children with haemoglobin A

\begin{tabular}{|c|c|c|c|}
\hline & $\mathrm{AA}(\mathrm{n}=16)$ & $\mathrm{SC}(\mathrm{n}=22)$ & $\mathrm{SS}(\mathrm{n}=24)$ \\
\hline Boys/ Girls & $8 / 8$ & $9 / 13$ & $14 / 10$ \\
\hline Age (yrs.) & $14.3 \pm 3.0$ & $15.1 \pm 2.6$ & $15 \pm 2.4$ \\
\hline Weight (kg) & $50 \pm 16$ & $50 \pm 13$ & $49 \pm 14$ \\
\hline Height (cm) & $162.0 \pm 0.1$ & $160.0 \pm 0.1$ & $162.0 \pm 0.1$ \\
\hline Body mass index $\left(\mathrm{kg} / \mathrm{m}^{2}\right)$ & $19.8(15.8 ; 21.2)$ & $18.8(17.6 ; 20.8)$ & $17.8(16.0 ; 20.0)$ \\
\hline SBP (mmHg) & $114 \pm 9$ & $112 \pm 14$ & $115 \pm 8$ \\
\hline DBP (mmHg) & $57 \pm 6$ & $61 \pm 9$ & $56 \pm 8$ \\
\hline MAP (mmHg) & $74.2(70.6 ; 81.3)$ & $75.0(69.5 ; 82.9)$ & $74.7(71.8 ; 79.5)$ \\
\hline PP (mmHg) & $57 \pm 9$ & $51 \pm 10$ & $59 \pm 12^{\#}$ \\
\hline Heart rate (beats/min) & $77 \pm 12$ & $76 \pm 10$ & $84 \pm 12^{\#}$ \\
\hline Haemoglobin (g/dl) & - & $11.5 \pm 0.8$ & $8.4 \pm 1.2 \# \# \#$ \\
\hline Haematocrit (\%) & - & $33.0 \pm 3.2$ & $25.4 \pm 3.8 \# \# \#$ \\
\hline Blood viscosity (mPa.s) & - & $6.0 \pm 1.0$ & $4.8 \pm 0.8 \# \# \#$ \\
\hline Lactate dehydrogenase (IU/L) & - & $293 \pm 85$ & $546 \pm 172 \# \# \#$ \\
\hline Foetal haemoglobin (\%) & - & $2.3(1.4 ; 3.6)$ & $6.8(3.6 ; 10.3) \# \# \#$ \\
\hline Bilirubin & - & $20.5(14.0 ; 32.0)$ & $44.0(31.5 ; 78.5) \# \# \#$ \\
\hline Reticulocytes (\%) & - & $2.9 \pm 1.1$ & $9.9 \pm 4.3 \# \# \#$ \\
\hline Haemolytic index (a.u.) & - & $-0.72 \pm 0.35$ & $0.69 \pm 0.93 \# \# \#$ \\
\hline $\begin{array}{l}\text { Aspartate Aminotransferase } \\
\text { (IU/L) }\end{array}$ & - & $23.8 \pm 8.6$ & $35.4 \pm 13.7 \# \#$ \\
\hline
\end{tabular}

Values are given as mean \pm standard deviation and median $\left(25^{\text {th }}\right.$ and $75^{\text {th }}$ percentiles $)$.

AA, healthy controls; SS, children with homozygous sickle cell disease; SC, children with sickle cell haemoglobin-C disease; SBP, systolic blood pressure; DBP, diastolic blood pressure, MAP, mean arterial blood pressure; PP, pulse pressure. ${ }^{*} P<0.05$ vs. AA; ${ }^{\#} P<0.05$ vs. SC; ${ }^{\#} P<0.01$ vs. SC; ${ }^{\# \# ~} P<0.001 v s$. SC. Blood sampling was not possible in controls because of ethical restriction. Reference values for haematological parameters and blood viscosity in controls can be found in Renoux et al 2016 [67]. 
Table 2. Skin blood flow variations in response to local heating in children with sickle cell disease and control subjects

\begin{tabular}{lccc}
\hline & AA & SC & SS \\
\hline Baseline flow (mV/mmHg) & $2,00 \pm 1.50$ & $2.22 \pm 1.22$ & $3.46 \pm 1.62 * * \#$ \\
Peak flow (mV/ mmHg) & $4.82 \pm 1.25$ & $4.32 \pm 1.65$ & $4.68 \pm 1.23$ \\
Plateau flow (mV/ mmHg) & $4.43 \pm 1.42$ & $3.65 \pm 1.58$ & $3.72 \pm 1.72$
\end{tabular}

Values are given as mean \pm standard deviation.

AA, healthy controls; SS, children with homozygous sickle cell disease; SC, children with sickle cell haemoglobin- $\mathrm{C}$ disease.

Baseline, Peak and Plateau blood flow are expressed as cutaneous vascular conductance.

$* P<0.05$ vs. AA; ** $P<0.01$ vs. AA; *** $P<0.001$ vs. AA; $\# P<0.05$ vs $\mathrm{SC}$, using a one-way analysis of variance followed by a Newman-Keuls post-hoc test. 


\section{Figure legends}

Figure 1: Tracing of the mean skin blood flow (expressed as $\mathrm{CVC}$ in $\mathrm{mV} / \mathrm{mmHg}$ ) in response to local heating to $42^{\circ} \mathrm{C}$ in children with sickle cell SC, SS and control children. Above, percentage increase in skin blood flow from baseline up to peak and plateau in SS, SC patients and controls. Groups were compared using Kruskall Wallis Anova. * $P<0.05$ vs. AA; $* * P<0.01$ vs. AA; *** $P<0.001$ vs. AA

Figure 2: Carotid to radial pulse wave velocity (PWV) measured by applanation tonometry in children with sickle haemoglobin $\mathrm{C}$ and haemoglobin $\mathrm{S}$ disease and control subjects (AA). Means were compared between the three groups using one-way analysis of variance followed by a Newman-Keuls post-hoc test. * $P<0.05$ vs. AA.

Figure 3: (A) Comparison of physical activity energy expenditure (PAEE) between children with sickle cell SC and SS disease and in control (AA) subjects using one-way analysis of variance followed by a Newman-Keuls post-hoc test. ${ }^{* *} P<0.01 v s$. AA. (B) Percentage of the predicted six minute walk distance in children with sickle haemoglobin $\mathrm{C}$ disease and children with sickle cell anaemia. The two groups were not different. Obtained using unpaired Student $t$ test. 